\title{
Johne's disease: reliability of environmental sampling to characterize Mycobacterium avium subspecies paratuberculosis (MAP) infection in beef cow-calf herds
}

\author{
W. KLAWONN ${ }^{1}$, E. EINAX ${ }^{2}$, R. PÜTZSCHEL ${ }^{3}$, M. SCHMIDT ${ }^{3}$ AND K. DONAT ${ }^{2 *}$ \\ ${ }^{1}$ Animal Health Service, State Laboratory of Rhineland-Palatinate, Koblenz, Rhineland-Palatinate, Germany \\ ${ }^{2}$ Animal Health Service, Thuringian Animal Diseases Fund, Jena, Thuringia, Germany \\ ${ }^{3}$ Animal Health Service, Saxon Animal Diseases Fund, Dresden, Saxony, Germany
}

Received 8 September 2015; Final revision 8 March 2016; Accepted 10 March 2016;

first published online 20 April 2016

\section{SUMMARY}

Environmental samples are considered to be a cost-effective method of identifying Mycobacterium avium subsp. paratuberculosis (MAP)-positive dairy herds, but evidence for beef cow-calf herds is weak. This study aims at evaluating this approach in a total of 20 German herds that were characterized by individual faecal samples $(n=2545)$ of all cows. For 14 MAPpositive herds having at least one MAP-positive animal, the within-herd prevalence was calculated from concurrent individual faecal culture-based testing. Six herds certified as 'MAP free' based on the negative results of previous years served as MAP-negative controls. On average, six environmental samples were taken at the end of winter from areas with high cow traffic and tested for MAP by faecal culture. According to the environmental samples, nine $(64 \cdot 3 \%)$ out of the 14 MAP-positive cow-calf herds were infected. The percentage of positive environmental samples and the apparent within-herd prevalence (Spearman's $P=0 \cdot 73, P<0 \cdot 001$ ) as well as the herd-level test results (positive and negative) and the herd's status based on individual testing (Fisher's exact test, $P=0.014$ ) showed a positive association. Considering limitations in low-prevalence herds, MAP-positive beef cow-calf herds are detectable by environmental samples in temperate climate zones.

Key words: Epidemiology, faecal culture, herd-level diagnosis, infectious disease control Mycobacterium avium subsp, paratuberculosis (MAP).

\section{INTRODUCTION}

The first description of samples taken from an animal's environment in order to prove a herd's paratuberculosis infection was done in the early 1990s. Approximately 50 environmental samples were taken per farm from ten farms with paratuberculosis-infected herds and one further dairy herd in Pennsylvania; 15-20 from designated locations within the barn, 20-30 samples

\footnotetext{
* Author for correspondence: Dr K. Donat, Thüringer Tierseuchenkasse, Victor-Goerttler-Straße 4, D-07745 Jena, Germany. (Email: kdonat@thueringertierseuchenkasse.de)
}

from the fields, creek banks, pastures and yards [1]. Mycobacterium avium subsp. paratuberculosis (MAP) was found in 5/11 farms with a recent history of Johne's disease. Most of the positive samples were taken from pastures and yards. The highest frequency of positive cultures occurred in farms with the largest number of heavily infected cattle. A markedly larger number of farms were tested for the first time in 80 herds known to be infected and 28 herds known to be uninfected from voluntary Johne's disease programmes in Minnesota [2]. Individual animal faecal samples from up to 100 cows from each farm were cultured in pools of five cows and compared with the results of 
two environmental faecal samples (EFS) per farm on average. Seventy-eight per cent of the herds known to be infected and one of the unsuspicious herds showed a positive reaction by EFS culture. Examinations of EFS for MAP by use of faecal culture or polymerase chain reaction (PCR) has proved to be a suitable method for the evaluation of Johne's disease status in dairy cattle herds in subsequent examinations [3-8]. By contrast, there are insufficient studies regarding the suitability of this approach for the evaluation of a beef cow-calf herd's situation [9]. This joint research project, involving three federal states in Germany, aimed to obtain the first experience in sampling and validity of EFS in cow-calf operations. This study is, to the best of our knowledge, the first within Europe and Germany, and possibly worldwide, that deals with this topic in beef cow-calf herds.

\section{MATERIAL AND METHODS}

\section{Study population}

A total of 20 cow calf herds (Simmental, Limousin, Charolais or cross-breed herds), monitored by the animal health services of the federal states Rhineland-Palatinate, Saxony and Thuringia, were included in the study. Herds from Thuringia and Saxony were enrolled into a voluntary control programme as described previously [10]. However, in Rhineland-Palatinate a paratuberculosis control programme is not implemented. The total herd size ranged between 30 and 515 (median 195.5). During winter all herds used a stable or an open-front loose barn, and pasture during the rest of the year. Calving season differed between herds (Table 1). According to the current within-herd prevalence, herds with a high $(n=6)$ and a low $(n=8)$ within-herd prevalence were chosen for comparison with six herds that were certified as 'herds not suspected of having paratuberculosis'. In five of the latter herds all cows had been monitored for 3 years by annual individual faecal culture without any positive result, one herd was also tested by antibody ELISA over 7 years instead of first faecal culture without any positive result.

\section{Environmental and individual sampling}

On the 20 farms, six EFS had been taken on average from areas with high cow traffic (feed alley, drinking system, running alleyway), from the holding pen in the barn, the calving pen, the manure store as well as from the winter camp, mainly during the end of winter holding. An adequate number of at least five subsamples were manually taken using new latex safety gloves and a disinfected spatula from each location. The number of samples were primarily chosen according to the holding compartments. Technical reasons like grouping within the herd, the availability of manure at distinct locations and the contamination of manure with soil or straw had some impact as well. Therefore, the number of representative locations that could be sampled varied accordingly from herd to herd $(\min 1, \max 14$, Table 1$)$. In the first instance areas with high cow traffic were sampled in all herds. The subsamples were placed together in a sterile $125 \mathrm{ml}$ plastic cup with a screw cap (Urine cup UB 100, Labortechnik GmbH, Germany).

At about the same time as taking EFS, the herd's cows were individually sampled and tested by culture $(n=2545)$. All cows in the herd were sampled. The individual animal faecal samples were always taken with a new examination glove from the rectum. All faecal samples were wiped into a sterile plastic cup as described above which contained a barcode. For the animal's identification, an EDP-readable form was used to complete the cow's ten-digit ear tag number. EFS as well as individual samples were transported in a cooler to the laboratory and stored until examination at $-20^{\circ} \mathrm{C}\left( \pm 2{ }^{\circ} \mathrm{C}\right)$ for $1-4$ weeks.

\section{Faecal culture}

All samples from Rhineland-Palatinate and Thuringia were examined in the laboratory of the Thuringian animal health service in Jena and those from Saxony in the Saxon state laboratory for public and veterinary health in Dresden. The cultural examination of the individual animal samples as well as the EFS was performed according to the official manual of diagnostic procedures published by the Friedrich-Loeffler-Institut, German Federal Research Institute of Animal Health [11]. The differentiation of suspicious colonies was done via Ziehl-Neelsen staining as well as subculture (testing of the mycobactin-dependent growth) and an IS900 PCR [12]. Inconclusive PCR results due to inhibited PCR runs were repeated after dilution of the extracted DNA. All suspicious colonies were identified as MAP. Repeated cultivations were performed when bacterial and fungal growth of contaminants led to suspicion of overgrowth and reduced interpretability of the culture. Non-evaluable samples due to contamination were not taken into consideration. 
Table 1. Herd characteristics and detection of Mycobacterium avium ssp. paratuberculosis (MAP) in individual faecal samples and environmental faecal samples in 20 beef cow-calf operations

\begin{tabular}{|c|c|c|c|c|c|c|c|c|c|c|}
\hline \multirow[b]{2}{*}{ Herd } & \multirow[b]{2}{*}{ Region* } & \multirow[b]{2}{*}{$\begin{array}{l}\text { Calving } \\
\text { season }\end{array}$} & \multirow[b]{2}{*}{ Breed } & \multirow[b]{2}{*}{$\begin{array}{l}\text { Total } \\
\text { herd } \\
\text { size }\end{array}$} & \multicolumn{3}{|c|}{ Individual faecal samples } & \multicolumn{3}{|c|}{ Environmental faecal samples } \\
\hline & & & & & $\begin{array}{l}\text { Samples } \\
(n)\end{array}$ & $\begin{array}{l}\text { MAP } \\
\text { positive } \\
(n)\end{array}$ & $\begin{array}{l}\text { MAP } \\
\text { positive } \\
(\%)\end{array}$ & $\begin{array}{l}\text { Samples } \\
(n)\end{array}$ & $\begin{array}{l}\text { MAP } \\
\text { positive } \\
(n)\end{array}$ & $\begin{array}{l}\text { MAP } \\
\text { positive } \\
(\%)\end{array}$ \\
\hline 1 & $\mathrm{TH}$ & Spring & Simmental & 30 & 22 & 0 & $0 \cdot 0$ & 3 & 0 & $0 \cdot 0$ \\
\hline 2 & $\mathrm{TH}$ & Winter & Simmental & 152 & 84 & 0 & $0 \cdot 0$ & 4 & 0 & $0 \cdot 0$ \\
\hline 3 & $\mathrm{TH}$ & $\begin{array}{l}\text { Autumn/ } \\
\text { winter }\end{array}$ & Simmental & 53 & 28 & 0 & $0 \cdot 0$ & 3 & 0 & $0 \cdot 0$ \\
\hline 4 & $\mathrm{TH}$ & Spring & Simmental & 320 & 201 & 0 & $0 \cdot 0$ & 7 & 0 & $0 \cdot 0$ \\
\hline 5 & $\mathrm{TH}$ & $\begin{array}{l}\text { Spring/ } \\
\text { summer }\end{array}$ & Simmental & 71 & 61 & 0 & $0 \cdot 0$ & 3 & 0 & $0 \cdot 0$ \\
\hline 6 & $\mathrm{RP}$ & Year-round & $\begin{array}{l}\text { Simmental, } \\
\text { Limousin, } \\
\text { cross-breed }\end{array}$ & 153 & 83 & 0 & $0 \cdot 0$ & 10 & 0 & $0 \cdot 0$ \\
\hline 7 & $\mathrm{SN}$ & Winter & $\begin{array}{l}\text { Simmental, } \\
\text { Limousin }\end{array}$ & 175 & 118 & 1 & $0 \cdot 9$ & 14 & 0 & $0 \cdot 0$ \\
\hline 8 & $\mathrm{SN}$ & Year-round & cross-breed & 487 & 368 & 9 & $2 \cdot 5$ & 5 & 1 & $20 \cdot 0$ \\
\hline 9 & $\mathrm{TH}$ & $\begin{array}{l}\text { Autumn/ } \\
\text { winter }\end{array}$ & Charolais & 286 & 121 & 3 & $2 \cdot 5$ & 6 & 2 & $33 \cdot 3$ \\
\hline 10 & $\mathrm{SN}$ & Spring & $\begin{array}{l}\text { Simmental, } \\
\text { Limousin, } \\
\text { cross-breed }\end{array}$ & 515 & 203 & 7 & $3 \cdot 5$ & 11 & 0 & $0 \cdot 0$ \\
\hline 11 & $\mathrm{RP}$ & Year-round & Limousin & 216 & 82 & 3 & $3 \cdot 5$ & 3 & 1 & $33 \cdot 3$ \\
\hline 12 & $\mathrm{TH}$ & $\begin{array}{l}\text { Spring/ } \\
\text { summer }\end{array}$ & Limousin & 470 & 270 & 10 & $3 \cdot 7$ & 4 & 0 & $0 \cdot 0$ \\
\hline 13 & $\mathrm{RP}$ & $\begin{array}{l}\text { Summer/ } \\
\text { autumn }\end{array}$ & Limousin & 167 & 54 & 2 & $3 \cdot 7$ & 1 & 0 & $0 \cdot 0$ \\
\hline 14 & $\mathrm{TH}$ & Winter & Simmental & 260 & 183 & 7 & $3 \cdot 8$ & 7 & 0 & $0 \cdot 0$ \\
\hline 15 & SN & $\begin{array}{l}\text { Spring/ } \\
\text { summer }\end{array}$ & $\begin{array}{l}\text { Simmental, } \\
\text { cross-breed }\end{array}$ & 318 & 195 & 9 & $4 \cdot 6$ & 6 & 1 & $16 \cdot 7$ \\
\hline 16 & $\mathrm{TH}$ & $\begin{array}{l}\text { Spring/ } \\
\text { summer }\end{array}$ & Limousin & 396 & 174 & 10 & $5 \cdot 7$ & 9 & 5 & $55 \cdot 6$ \\
\hline 17 & RP & Year-round & cross-breed & 95 & 54 & 4 & $7 \cdot 4$ & 3 & 3 & $100 \cdot 0$ \\
\hline 18 & $\mathrm{RP}$ & Year-round & $\begin{array}{l}\text { Limousin } \\
\text { cross-breed }\end{array}$ & 253 & 143 & 11 & $7 \cdot 7$ & 9 & 3 & $33 \cdot 3$ \\
\hline 19 & $\mathrm{RP}$ & $\begin{array}{l}\text { Spring/ } \\
\text { autumn }\end{array}$ & Others & 87 & 50 & 4 & $8 \cdot 0$ & 2 & 1 & $50 \cdot 0$ \\
\hline 20 & $\mathrm{TH}$ & $\begin{array}{l}\text { Spring/ } \\
\text { summer }\end{array}$ & Simmental & 95 & 51 & 22 & 43,1 & 7 & 4 & $51 \cdot 1$ \\
\hline
\end{tabular}

* TH, Thuringia; RP, Rhineland-Palatinate; SN, Saxony.

\section{Within-herd prevalence calculation and herd classification}

Herds defined as MAP positive were those that had at least one sample containing a proven cultural growth of MAP out of all examined individual animal faecal samples. Provided that farmers had a bovine population in several places, they were seen as one farm due to the extensive within-operation animal movement. The apparent within-herd prevalence of infected animals was calculated by dividing the number of faecal culture-positive samples by the number of tested individuals. According to other authors (e.g. [13, 14]), herds with a mean apparent MAP prevalence $\leqslant 5 \%$ were categorized as low-prevalence herds, and those above this threshold as high-prevalence herds.

A farm was declared as EFS positive if MAP was established in at least one of the farm's EFS.

\section{Statistical analysis}

Fisher's exact test [15] was used to verify the association of the farm's EFS results with the herd's status 


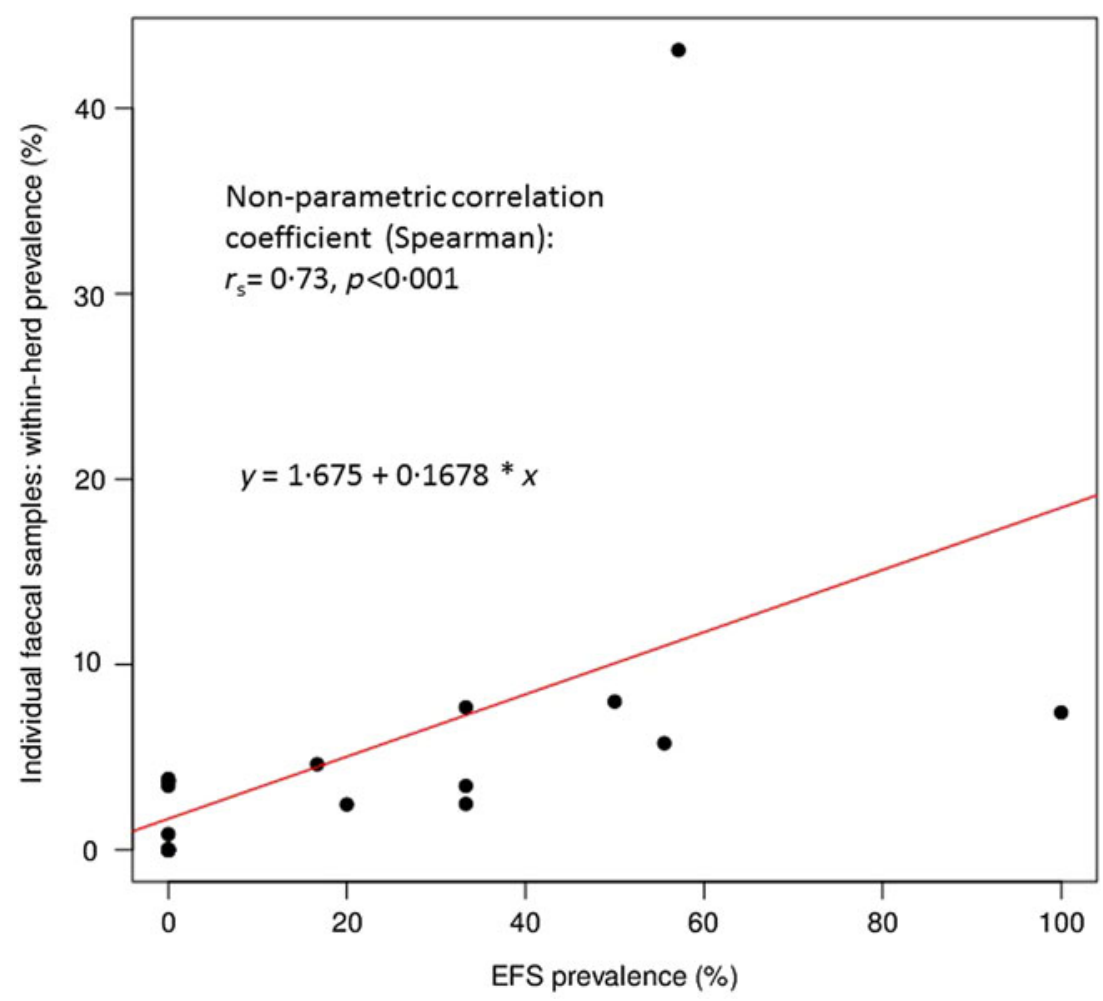

Fig. 1. Correlation between the percentage of positive environmental faecal samples (EFS) and the amount of positive individual faecal samples.

on the basis of individual animal faecal samples. The calculation of the non-parametric correlation coefficient according to Spearman [16] was used to describe the relationship between within-herd prevalence and the percentage of positive EFS per farm. Due to the high variation in the number of EFS between herds, the calculations were performed with and without farms with $<3$ EFS. Furthermore, in the analysis two farms with $<3$ EFS were excluded along with another herd with an extreme individual animal faecal prevalence, as it was considered to be an outlier. The significance level was specified as $P<0.05$. ' $\mathrm{R}$ ' statistical software was used for the calculations [17].

\section{RESULTS}

Table 1 shows the test results of the EFS and the individual animal faecal samples. Based on the results of the individual animal faecal samples, the 14 infected beef cow-calf herds were classified in two groups, i.e. farms with high $(>5 \%)$ and low $(\leqslant 5 \%)$ within-herd prevalence. The latter herds had a median of $3.5 \%$ $(\min 0.9 \%, \max 4 \cdot 6 \%)$ for their individual animal faecal prevalence; which was $7.7 \%(\min 5.8 \%$, max $43 \cdot 1 \%$ ) for the high-prevalence herds. The overall testing of 117 EFS by faecal culture showed positive results in $21(17.9 \%)$ samples. Sixteen of the positive samples came from high-prevalence herds whereas only five were from low-prevalence herds. The EFS of the six certified MAP-negative beef cow-calf herds did not show any MAP-positive result. However, within all high-prevalence herds, MAP was established in at least one EFS whereas in the EFS of the low-prevalence herds only four $(44 \cdot 4 \%)$ out of nine showed a MAP-positive result. In total, 9/14 MAP-positive cow-calf herds (64.3\%) were detected as infected due to examination of EFS. A significant positive relationship (Spearman's non-parametric correlation coefficient, $\left.r_{s}=0.73, P<0.001\right)$ was detected between the percentage of positive EFS and the amount of positive individual animal faecal samples (see Fig. 1). The re-analysis without the two farms with $<3$ EFS collected and the farm with an extreme individual animal faecal prevalence resulted in $r_{s}=$ $0.69(P<0 \cdot 01)$. Fisher's exact test also showed significant associations $(P=0 \cdot 014)$ between the dichotomous EFS results at the farm level and of the herd's status due to individual animal faecal sample testing (positive and negative). The test remained significant after exclusion of the two farms with $<3$ EFS collected and one 
Table 2. Detection of Mycobacterium avium ssp. paratuberculosis (MAP) in environmental faecal samples in the six cow-calf herds certified as 'none suspecting of having paratuberculosis' and the 14 MAP-positive beef cow-calf herds with respect to the location of sampling

\begin{tabular}{|c|c|c|c|c|c|c|c|}
\hline \multirow[b]{2}{*}{ Location of sampling } & \multicolumn{3}{|c|}{ MAP unsuspicious herds } & \multicolumn{4}{|c|}{ MAP-positive herds } \\
\hline & $\begin{array}{l}\text { Samples } \\
(n)\end{array}$ & $\begin{array}{l}\text { Herds } \\
(n)\end{array}$ & $\begin{array}{l}\text { MAP } \\
\text { positive }(n)\end{array}$ & $\begin{array}{l}\text { Samples } \\
(n)\end{array}$ & $\begin{array}{l}\text { Herds } \\
(n)\end{array}$ & $\begin{array}{l}\text { MAP } \\
\text { positive }(n)\end{array}$ & $\begin{array}{l}\text { MAP } \\
\text { positive }(\%)\end{array}$ \\
\hline Calving pen & & & & 5 & 3 & 0 & $0 \cdot 0$ \\
\hline Pasture/windbreak & 2 & 1 & 0 & 2 & 2 & 0 & $0 \cdot 0$ \\
\hline $\begin{array}{l}\text { Areas of high animal traffic (feeding } \\
\text { alleyways, watering place, yards) }\end{array}$ & 12 & 5 & 0 & 36 & 10 & 9 & $25 \cdot 0$ \\
\hline Group pens (embedding) & 7 & 4 & 0 & 27 & 7 & 1 & $3 \cdot 7$ \\
\hline Sick cow pens & & & & 2 & 2 & 2 & $100 \cdot 0$ \\
\hline Dunghill & & & & 2 & 2 & 1 & $50 \cdot 0$ \\
\hline Boot soles & 2 & 2 & 0 & 4 & 3 & 3 & $75 \cdot 0$ \\
\hline Cattle crush's floor, alley and forcing pen & 7 & 1 & 0 & 8 & 2 & 4 & $50 \cdot 0$ \\
\hline Winter camp & & & & 1 & 1 & 1 & $100 \cdot 0$ \\
\hline
\end{tabular}

farm with an extreme individual animal faecal prevalence $(P=0.035)$.

As inferred from Table 2, most samples were taken in areas with high animal traffic in infected farms $(40.0 \%)$ as well as unsuspicious ones (41.4\%). MAP was found in $25 \%$ of the samples taken from infected farms.

With regard to just the high-prevalence infected herds, there is a share of $56 \cdot 3 \%$ (9/16 samples) taken from areas with high cow traffic that tested positively. In addition, positive samples were taken from the examiners' boot soles, the cattle crush floor, its alley and forcing pen, as well as from pens holding sick cows. Thirty-five of the 51 samples that were taken in other areas than those with a high animal traffic were from low-prevalence farms and only two of the samples showed a positive result: the first taken from a group pen, the other from a pen used by animals suspected of Johne's disease.

\section{DISCUSSION}

The present study is the first in Europe, possibly worldwide, that deals with the use of EFS to identify a MAP infection in beef cow-calf herds: six herds that were certified as 'herds not suspected of having paratuberculosis' due to repeated herd examinations in individual faecal culture were compared with 14 MAP-positive cow-calf herds. The within-herd prevalence in these herds ranged between $0.9 \%$ and $43 \cdot 1 \%$ (median 3.8\%), hence nine of them are low-prevalence and five high prevalence herds. An American study examined 380 beef cow-calf herds with $10 \cdot 371$ cows serologically; $7 \cdot 9 \%$ of the herds and $0.4 \%$ of the cows, respectively, were detected as positive by ELISA, but an underestimation of the prevalence due to limited sensitivity of the ELISA test was assumed [18]. Other authors tested 840 cows serologically and by faecal culture (pools of five with individual animal follow-up examinations of positive pools) [19]. Although MAP was only proven in the faeces of two animals, Bayesian estimates of true prevalence indicated that $20 \%$ [95\% confidence interval (CI) 3-38] of herds had at least one MAP-positive cow with a within-herd prevalence of positive herds of $22 \%$ (95\% CI 8-42). In a Swiss study, a within-herd prevalence of $6.4 \%$ in seven infected beef herds was detected by faecal culture and PCR in pools of three [20]. The number of animals sampled in these herds ranged from 25 to 130 with an average number of 56 animals aged $>1$ year. In all of the 20 cow-calf herds of the present study, on average six EFS were tested culturally. The samples were collected simultaneously $( \pm 1$ month) at the last individual sampling. The results show that MAP-infected cow-calf herds with a withinherd prevalence of $5 \%$ can be precisely identified by examination of EFS. According to an examination of Canadian dairy herds, EFS taken in spring and summer are more likely to be positive than samples taken during the winter months [21]. Next to possible influences of temperature and humidity, the examiners stated differences in the taking of samples as possible reasons, i.e. a lower number of samples taken from liquid manure lagoons and pits. Alternatively, a shorter 
length of MAP survival was reported at high temperatures due to intensive insolation [22, 23]. Hence, the beginning of spring at the ending of the cold season seems to be the ideal time for taking EFS from cowcalf herds in temperate climate zones. At this point, a lot of cow-calf herds are still kept in stables, or the cow's winter camp can be used for sampling, respectively. Depending on within-herd prevalence the reliability of the examination of EFS of cow-calf herds is, at this point, comparable with that of dairy cattle herds. Out of 31 MAP-positive herds, 22 (71\%) proved to be positive by EFS, and all dairy herds with a within-herd prevalence $>5 \%$ were EFS positive in a German study [7]. North American studies estimate the herd-level sensitivity of EFS taken from areas with high animal traffic in dairy herds at $68-80 \%$ [9, $24,25]$. The herd-level sensitivity of $64 \cdot 3 \%$ stated in the present study is comparable to these former data; the slightly lower value might be due to the relatively low number of tested herds. A specificity of $100 \%$ can be assumed for faecal culture as the test method, because the cultural examination of faeces can be seen as 'gold standard' and speciation with IS900 PCR in combination with cultural morphology and Ziehl-Neelsen staining guarantee very high diagnostic precision. The negative EFS results throughout from herds certified as not suspected of having paratuberculosis justify this assumption. By sequential acquisition of EFS, the diagnostic precision can be further increased [26, 27]. In doing so, the infection can be proven in herds with a lower within-herd prevalence. A longitudinal study in seven Canadian dairy herds identified a lower limit of within-herd prevalence at $2 \%$ for the proof of infection by EFS [5]. Another Canadian study compared the results of EFS taken at 3-month intervals with the examination of pools of five taken at bi-annual intervals with a follow-up examination of positive pools in the within-herd prevalence. Due to sequential acquisition, the sensitivity was able to be increased from $71 \%$ at a single EFS examination to $90 \%$ at an examination performed six times in $>30$ herds. However, a loss of specificity from $99 \%$ to $96 \%$ resulted from sampling six times [8]. Almost the same results were achieved in eight German herds with sequential sampling of gauze pads from the soles of boots (i.e. boot swabs): over 3 years a total 130 samples were taken by walking the paths of lactating cows in the barn; 58/64 boot swabs $(90 \cdot 6 \%)$ were from four infected herds. In the four herds that were assumed to be negative due to missing positive test results by individual faecal culture $1 \cdot 5 \%$ of the swabs showed a positive result by faecal culture. Presumably, cows in one of the latter herds were not completely MAP negative, but the within-herd prevalence was low. Alternatively, these positive results might have been caused by MAP new entries of birds and other wild animals [27]. All things being equal, the transmittal from bovine herds to wild animals seems to be more likely than the other way around [28-31]. On the other hand, positive results in the ELISA of unsuspicious farms might have been caused by unspecific reactions due to other mycobacteria [32-34].

The cow alleyways as well as the manure store or liquid manure lagoons and pits turned out to be highly efficient for sampling [2, 21, 35, 36]. For our examination, most of the samples from infected $(40.0 \%)$ as well as unsuspicious $(41.4 \%)$ herds were taken in areas with high cow traffic. MAP was established in $25 \%$ of the infected farms. Considering only the infected farms with high prevalence, the detection rate doubled to $56 \cdot 3 \%$. By contrast, for alleyways of dairy cattle herds, detection rates of $40-53 \%$ were found $[4,5,7,21,35]$. The detection rate for dairy cattle might also be related to husbandry, a higher number of heavy shedders within the herd and higher within-herd prevalence. For dairy herds with a high $(35 \%)$ to medium $(16 \%)$ prevalence due to individual animal's faecal culture a sensitivity of $100 \%$ and $95 \%$ were calculated, respectively, when four EFS per farm were taken; however, when examining 10 EFS from herds with a prevalence of $5 \%$ this only achieved 38\% [37]. For the present examination the within-herd prevalence showed $>10 \%$ in only one herd. In our examination, positive samples were also taken from the soles of the Wellington boots of the examiners, the cattle crush floor or its alley and forcing pen as well as from sick cow pens. These locations can indeed be seen as suitable for sampling; however, the relatively low number of samples from these areas should be considered. In seven Michigan dairy herds positive EFS were gained beyond areas with a high animal traffic or the manure or liquid manure stores only in farms with within-herd prevalence near or above 5\% [5]. By contrast, other publications stress the necessity of sampling from different areas for farms with a low within-herd prevalence [7]. In the present examination of cow-calf herds, a positive sample was taken from a group pen's floor in low prevalently infected herds, which was one of two positive samples from this farm with a prevalence of $2 \cdot 5 \%$ calculated from individual testing by faecal culture. 
Considering that this study focuses on the probability of having test-positive EFS with respect to apparent within-herd prevalence, the large variation in the number of samples tested in herds is expected to strongly affect test performances, particularly sensitivity. Herds were very different regarding herd size and rearing conditions. Therefore, it was not possible to specify the sampling locations in advance as in previous studies performed in dairy herds [38], and the number of samples per farm varied between 1 and 14. The number of samples primarily varied according to the holding compartments of the herds. Furthermore, technical reasons such as grouping within the herd as well as the availability of manure at distinct locations and the contamination of manure with soil or straw influenced the sampling in a specific herd. As a study evaluating the use of boot swabs and liquid manure samples for herd-level diagnosis of paratuberculosis [10], we demonstrated a good sensitivity of EFS even if only one or two samples per herd were analysed. Hence, herds with only few EFS were not excluded from the initial analysis. In a second analysis both herds with low numbers of EFS were omitted from analysis in order to reduce the influence of the large variation in number of samples. One herd with a very high individual animal faecal prevalence was also excluded, because it was considered as an outlier. These changes resulted in a minor reduction of Spearman's rank correlation coefficient that still demonstrated a significant relationship between the EFS test results and the individual animal faecal prevalences. Despite this, our study demonstrates that a predefinition of sampling locations or the number of samples is more challenging in beef cow-calf herds than in dairy herds. Considering the fact that the number of EFS collected at one farm visit influences the diagnostic sensitivity of the EFS approach [21], a minimum number of EFS collected per farm visit should be ensured to avoid a drop in sensitivity. Regarding the results of this study and previous studies $[21,38]$, a minimum number of three EFS seems to be adequate. If the on-farm situation does not allow an adequate sampling at three different types of location, unaccessible samples should be replaced by others [21].

Other authors also observed an increase of the number of MAP-positive EFS and thus of the method's sensitivity in dairy herds in relation to a rising within-herd prevalence $[1,2,7,8]$. Recently, this association was described by a logistic regression model and used to calculate thresholds of the withinherd-prevalence that allow the identification of a herd as MAP positive [38]. Corresponding evidence was also given when performing a sequential taking of boot swabs [27], and the appropriate logistic regression model led to a within-herd prevalence threshold of $\sim 4 \%$ for single sampling of a boot swab and liquid manure sample, when faecal culture and a real-time PCR were applied simultaneously [10]. The present examination of cow-calf herds has also shown a positive relationship between the percentage of positive EFS and the apparent within-herd prevalence estimated by individual faecal culture testing. Hence, EFS can not only be used for the detection of infected herds, but also for supporting the sanitation of infected farms. In this manner, the success or failure of hygienic measures can be established and elucidated to the animal owners. Furthermore, this approach can be used in monitoring programmes and in studies to estimate herd-level prevalence of MAP infection in a region or country. If the establishment of appropriate control programmes at the regional or federal level proves successful, the danger of a new introduction of the infectious agent into a herd by the purchase of animals would finally decrease for beef cow-calf as well as dairy herds due to the testing of herds by EFS. In a recent Swiss study, purchase of animals was identified as the most important risk factor overall followed by contact of heifers and calves with faecal material from adult animals, but both factors were not significant for the seven examined beef herds in their study [20]. It can be stated that the purchase of cattle into the stock should be rated as an important risk factor whereas the relevance of wild animals or other domestic animals for the infection's transmission is not measurable [31]. According to a model calculation, after two sequenced negative tests of EFS, the probability of a cow's individual faecal culture being positive is already $<1 \%$ [8]. Herds with a medium to high within-herd prevalence can already be very precisely identified after a single EFS examination as probably having the highest risk of new infection in free herds. In addition, the examination of EFS in herds with high, medium or low within-herd prevalence is the most economic method for identification of MAP-positive herds [37]. More research is needed to clarify which sampling protocols are ideal for beef cow-calf herds.

\section{ACKNOWLEDGEMENTS}

This joint research project was undertaken and financed by the animal health services of three 
German federal states. The authors thank the Saxon Veterinary State Laboratory and Laboratory of the Thuringian animal health service and their staff for support. Furthermore, the authors gratefully acknowledge the financial support from the animal disease funds of Rhineland-Palatinate, Saxony and Thuringia, respectively. Finally, the authors thank the participating cattle farmers and all veterinarians who collected samples.

\section{DECLARATION OF INTEREST}

None.

\section{REFERENCES}

1. Rosenberger $\mathbf{A E}$, et al. Isolation of M. paratuberculosis from the environment of dairy farms with a known history of Johne's disease. Third International Colloquium on Paratuberculosis. 1991 (www.paratuberculosis.info/ proc3/page440.htm). Accessed 20 May 2015.

2. Raizman EA, et al. The distribution of Mycobacterium avium ssp. paratuberculosis in the environment surrounding Minnesota dairy farms. Journal of Dairy Science 2004; 87: 2959-2966.

3. Berghaus RD, et al. Environmental sampling for detection of Mycobacterium avium ssp. paratuberculosis on large California dairies. Journal of Dairy Science 2006; 89: 963-970.

4. Lombard JE, et al. Evaluation of environmental sampling and culture to determine Mycobacterium avium subspecies paratuberculosis distribution and herd infection status on US dairy operations. Journal of Dairy Science 2006; 89: 4163-4171.

5. Pillars RB, Grooms DL, Kaneene JB. Longitudinal study of the distribution of Mycobacterium avium subsp. paratuberculosis in the environment of dairy herds in the Michigan Johne's disease control demonstration herd project. Canadian Veterinary Journal 2009; 50:1039-1046.

6. Aly SS, et al. Reliability of environmental sampling to quantify Mycobacterium avium subspecies paratuberculosis on California free-stall dairies. Journal of Dairy Science 2009; 92: 3634-3642.

7. Donat K, Schau U, Soschinka A. Identification of Mycobacterium avium ssp. paratuberculosis infected dairy herds by environmental sampling. Berliner und Münchener Tierärztliche Wochenschrift 2011; 124: 360-367.

8. Lavers CJ, et al. Evaluation of environmental fecal culture for Mycobacterium avium subspecies paratuberculosis detection in dairy herds and association with apparent within-herd prevalence. Canadian Veterinary Journal 2013; 54:1053-1060.

9. Sweeney RW, et al. Paratuberculosis (Johne's disease) in cattle and other susceptible species. Journal of Veterinary Internal Medicine 2012; 26: 1239-1250.
10. Donat K, et al. Within-herd prevalence thresholds for the detection of Mycobacterium avium subspecies paratuberculosis-positive dairy herds using boot swabs and liquid manure samples. Epidemiology and Infection. Published online: 26 June 2015. doi:10.1017/ S0950268815000977.

11. Friedrich-Loeffler-Institut (FLI) - Bundesforschungsanstalt für Tiergesundheit. Amtliche Methodensammlung (www.fli. bund.de/fileadmin/dam_uploads/Publikationen/Amtliche Methodensammlung/FLI_Methodensammlung201305. pdf). Accessed 20 May 2015.

12. Englund S, et al. Single PCR and nested PCR with a mimic molecule for detection of Mycobacterium avium subsp. paratuberculosis. Diagnostic Microbiology Infectious Disease 1999; 33: 163-171.

13. van Schaik G, et al. Pooled fecal culture sampling for Mycobacterium avium subsp. paratuberculosis at different herd sizes and prevalence. Journal of Veterinary Diagnostic Investigation 2003; 15: 233-241.

14. Lavers CJ, et al. Evaluation of milk ELISA for detection of Mycobacterium avium subspecies paratuberculosis in dairy herds and association with withinherd prevalence. Journal of Dairy Science 2014; 97: 299-309.

15. Fisher R A. On the interpretation of $\chi^{2}$ from contingency tables, and the calculation of P. Journal of the Royal Statistical Society 1922; 85: 87-94.

16. Spearman C. The proof and measurement of association between two things. American Journal of Psychology 1904; 15: 72-101.

17. r-projekt-org. The R Project for Statistical Computing. (www.r-projekt.org). Accessed 20 May 2015.

18. Dargatz DA, et al. Prevalence of antibodies against Mycobacterium avium subsp. paratuberculosis among beef cow-calf herds. Journal of the American Veterinary Medical Association 2001; 219: 497-501.

19. Pruvot M, et al. Pathogens at the livestock-wildlife interface in Western Alberta: does transmission route matter? Veterinary Research 2014; 45: 18.

20. Künzler R, et al. Observed management practices in relation to the risk of infection with paratuberculosis and to the spread of Mycobacterium avium subsp. paratuberculosis in Swiss dairy and beef herds. BMC Veterinary Research 2014; 10: 132.

21. Wolf $\mathbf{R}$, et al. Sampling location, herd size, and season influence Mycobacterium avium ssp. paratuberculosis environmental culture results. Journal of Dairy Science 2015; 98: 275-287.

22. Whittington RJ, et al. Survival and dormancy of Mycobacterium avium subsp. paratuberculosis in the environment. Applied and Environmental Microbiology 2004; 70: 2989-3004.

23. Eppleston $\mathbf{J}$, et al. Environmental survival of Mycobacterium avium subsp. paratuberculosis in different climatic zones of Eastern Australia. Applied and Environmental Microbiology 2014; 80: 2337-2342.

24. Lombard JE, et al. Herd-level prevalence of Mycobacterium avium subspec. paratuberculosis infection in United States dairy herds in 2007. Preventive Veterinary Medicine 2013; 108: 234-238. 
25. Wolf R, et al. High herd-level prevalence of Mycobacterium avium subspecies paratuberculosis in Western Canadian dairy farms, based on environmental sampling. Journal of Dairy Science 2014; 97: 6250-6259.

26. Kalis CH, et al. Certification of herds as free of Mycobacterium paratuberculosis infection: actual pooled faecal results versus certification model predictions. Preventive Veterinary Medicine 2004; 65: 189-204.

27. Eisenberg T, et al. Boot swabs to collect environmental samples from common locations in dairy herds for Mycobacterium avium ssp. paratuberculosis (MAP) detection. Journal of Dairy Research 2013; 80: 485-489.

28. Corn JL, et al. Isolation of Mycobacterium avium subsp. paratuberculosis from free-ranging birds and mammals on livestock premises. Applied and Environmental Microbiology 2005; 71: 6963-6967.

29. Fritsch I, et al. Suspicion of Mycobacterium avium subsp. paratuberculosis transmission between cattle and wild-living red deer (Cervus elaphus) by multitarget genotyping. Applied and Environmental Microbiology 2012; 78: 1132-1139.

30. Elliott GN, et al. Environmental risk factors in the incidence of Johne's disease. Critical Reviews in Microbiology 2014 (http://informahealthcare.com/doi/ pdf/10.3109/1040841X.2013.867830). Accessed 20 May 2015.

31. Rangel SJ, et al. A systematic review of risk factors associated with the introduction of Mycobacterium avium spp. paratuberculosis (MAP) into dairy herds. Canadian Veterinary Journal 2015; 56: 169-177.
32. Crawford GC, et al. Mycobacterium avium subspecies paratuberculosis and Mycobacterium avium subsp. avium infections in a tule elk (Cervus elaphus nannodes) herd. Journal of Wildlife Disease 2006; 42: 715-723.

33. Norby B, et al. Environmental mycobacteria in soil and water on beef ranches: association between presence of cultivable mycobacteria and soil and water physicochemical characteristics. Veterinary Microbiology 2007; 124: 153-159.

34. Pruvot M, et al. Occurrence of Mycobacterium avium subspecies paratuberculosis and Neospora caninum in Alberta cow-calf operations. Preventive Veterinary Medicine 2014a; 117: 95-102.

35. Smith RL, et al. Environmental contamination with Mycobacterium avium subsp. paratuberculosis in endemically infected dairy herds. Preventive Veterinary Medicine 2011; 102: 1-9.

36. Kruze J, et al. Herd-level prevalence of Map infection in dairy herds of southern Chile determined by culture of environmental fecal samples and bulk-tank milk qPCR. Preventive Veterinary Medicine 2013; 111: 319-324.

37. Tavornpanich $\mathbf{S}$, et al. Simulation model for evaluation of testing strategies for detection of paratuberculosis in Midwestern US dairy herds. Preventive Veterinary Medicine 2008; 83: 65-82.

38. Donat K, et al. Detection of Mycobacterium avium subspecies paratuberculosis in environmental samples by faecal culture and real-time PCR in relation to apparent withinherd prevalence as determined by individual faecal culture. Epidemiology and Infection 2015; 143: 975-985. 